\title{
Appendiceal Orifice Inflammation in Ulcerative Colitis
}

\author{
Akira Hokama $\cdot$ Yasushi Ihama $\cdot$ Hiroshi Chinen · \\ Kazuto Kishimoto · Fukunori Kinjo · \\ Jiro Fujita
}

Published online: 6 June 2009

(C) Springer Science+Business Media, LLC 2009

\begin{abstract}
A 44-year-old man was diagnosed with distal ulcerative colitis (UC) when he had hematochezia at the age of 34 . He had had a few relapses on maintenance oral mesalazine. He desired a total colonoscopy in the clinical remission. Physical examination showed no abnormalities and routine laboratory tests were normal. Colonoscopy disclosed the appendiceal orifice inflammation (AOI) with reddish and friable mucosa and mucopus (Fig. 1). The remaining colorectum showed no inflammation. He remains well during the follow-up.
\end{abstract}

Since Cohen et al. first coined "ulcerative appendicitis" [1], AOI is uncommon but has increasingly been recognized in patients of distal UC. UC classically extends proximally from the rectum without skip lesions. Isolated AOI has been more frequently observed in patients with less extensive UC and is unlikely the result of patchy improvement due to treatments. The human appendix has long been recognized as a vestigial remnant. Although the pathogenesis of UC has not been fully clarified, clinical evidence has revealed the protective role of appendicectomy on onset and severity of UC [2,3], indicating the appendix as a priming site for UC [4]. Experimental studies of murine models have also shown that the appendix may serve a central role in antigen sampling and immunological signaling [5]. Therefore, further studies of AOI may unveil not only its clinical implication but also the immunopathogenesis of UC.

A. Hokama $(\bowtie) \cdot$ Y. Ihama $\cdot$ H. Chinen $\cdot$ K. Kishimoto · F. Kinjo - J. Fujita

First Department of Internal Medicine, University of the Ryukyus, 207 Uehara, Nishihara, Okinawa 903-0215, Japan e-mail: hokama-a@med.u-ryukyu.ac.jp

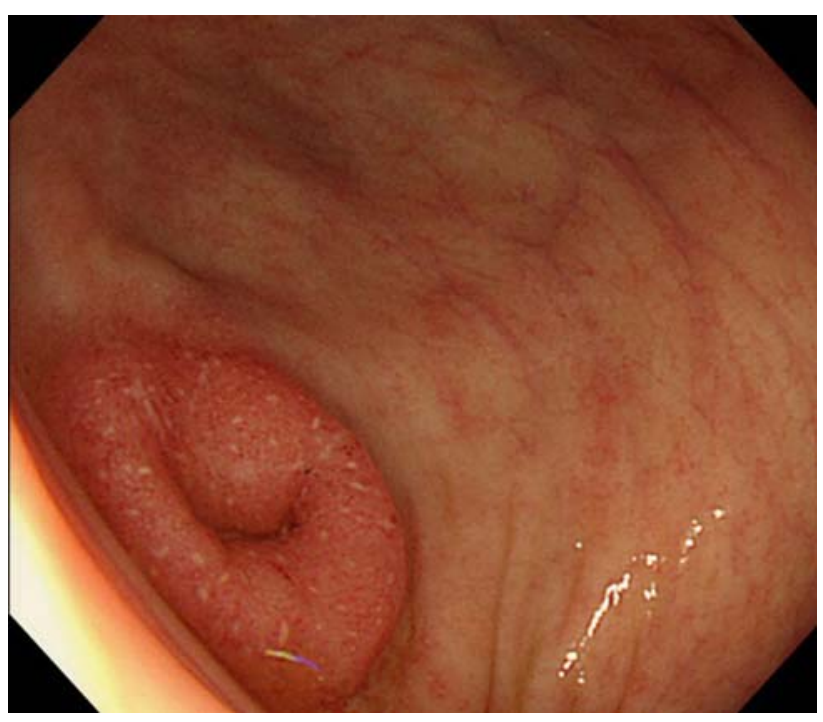

Fig. 1 Colonoscopy showing the appendiceal orifice inflammation

\section{References}

1. Cohen T, Pfeifer RB, Valensi Q. "Ulcerative appendicitis" occurring as a skip lesion in chronic ulcerative colitis: report of a case. Am J Gastroenterol. 1974;62:151-155.

2. Radford-Smith GL, Edwards JE, Purdie DM, et al. Protective role of appendicectomy on onset and severity of ulcerative colitis and Crohn's disease. Gut. 2002;51:808-813. doi:10.1136/gut.51.6.808.

3. Cosnes J, Carbonnel F, Beaugerie L, et al. Effects of appendicectomy on the course of ulcerative colitis. Gut. 2002;51:803-807. doi:10.1136/gut.51.6.803.

4. Spahn TW, Kucharzik T. Modulating the intestinal immune system: the role of lymphotoxin and GALT organs. Gut. 2004; 53:456-465. doi:10.1136/gut.2003.023671.

5. Mizoguchi A, Mizoguchi E, Chiba C, et al. Role of appendix in the development of inflammatory bowel disease in TCR- $\alpha$ mutant mice. J Exp Med. 1996;184:707-715. doi:10.1084/jem.184.2.707. 